\title{
Experience With PTFE 'Ecoflon' (Russia) Vascular Grafts in Surgery of Aortoiliac Lesionse
}

\author{
Michail Viktorovich Melhikov ${ }^{1}$, Aleksandr Emelyanovich Barsukov ${ }^{1}$, Vladimir Alexandrovich \\ Zelinskiy ${ }^{1}$, Oleg Viktorovich Isaulov ${ }^{1}$, Artur Urievich Apresyan ${ }^{1}$, Sergey Anatolievich Vinnichuk ${ }^{1}$
}

1) Department of Angiology and Vascular Surgery, I. Mechnikov State Medical Academy, Saint-petersburg, Russia

\section{Summary}

Objective: The choice of artificial conduit is issue of the day so far. The use of Dacron versus PTFE as a conduit in aortoiliac position is based on the preference of the surgeon. PTFE "Ecoflon" vascular grafts manufactured since 1994 may be used in surgery of aortoiliac lesions together with foreign analogues.

Material and Method: 197 executive patients with aortoiliac lesions were consecutively treated using linear or bifurcated PTFE "Ecoflon" vascular grafts. In-hospital (30-days) mortality, amputation rate, patency rate and complication rate were analysed in the early postoperative period. Primary patency, secondary patency, limb salvage, survival rates, infection complications and false aneurysms were assessed for estimate of long-term results. Histological study of distal anastamotic sites was performed in the patients with postoperative thrombotic events after re-intervention.

Results: 'Ecoflon' polytetrafluorethylene vascular grafts are highly biologically inert. This is confirmed by histological examination. Limb salvage, primary and secondary patency rates have demonstrated that PTFE "Ecoflon" vascular grafts provide long-term maintenance of adequate blood flow through bypass under favorable haemodinamic conditions. The rates of complications directly related to qualities of vascular conduit (graft infection, false aneurysms, bleeding from anastamotic sites) were compared with the data of published studies.

Conclusion: 'Ecoflon' PTFE vascular grafts are biologically inert prostheses, possessing structural porosity and no surgical porosity, with original arrangement of fibrils. Grafts can be sterilized using modern sterilization methods. In addition, they have favorable biomechanical properties (elasticity, extensibility, flexibility and durability). In our opinion, PTFE "Ecoflon" vascular grafts meet the requirements to "ideal vascular conduit" postulated by J.F. Vollmar in 1962.

Keywords: PTFE ‘Ecoflon’ vascular grafts, surgery of aortoiliac lesions, patency rate, limb salvage rate.

\section{Introduction}

The development of aortoiliac lesions surgery was impossible without creation and application of the synthetic vascular grafts because the use of autological materials or endarterectomy is limited or impossible. Since 1952, the Vinyon synthetic vascular grafts have been used in aortoiliac surgery. ${ }^{(1)}$ The further progress of vascular surgery was closely connected with improvement of synthetic vascular grafts. 
In the 50-60s of past century, the textile prostheses based on Dacron, Lavsan, Phthorlavsan, Terilen, Teflon and others appeared. In the 70s in USA, the "Gore" Company started the production of polytetrafluoroethylene (PTFE) vascular prostheses. Later on, repetition work of prostheses from PTFE was assimilated by several other companies like "Baxter", "Suler Vascutek", "Atrium", "B-Braun". However, their high cost limited their wide use in different countries. In the Russian Federation, the production of PTFE vascular conduit was started in 1994, when "Ecoflon" presented the first version of linear vascular grafts while bifurcate vascular grafts were presented in 1996. Nowadays, I.P. Dudanov et al. (2007) ${ }^{[2]}$, A.G. Evdokimov et al. (2001) ${ }^{[3]}$, P.O. Kasanchyan et al.(2001) ${ }^{[4]}$, A.V. Maximov et al. $(2006)^{[5]}$, M.V. Melnikov et al. $(2008)^{[6]}$ have rich experience with PTFE "Ecoflon" (Russia) vascular grafts in aortoiliac lesions. They appreciated these grafts highly.

Analysis of published data concerning the use of different kinds of conduits in surgery of aortoiliac lesions has not shown any significant difference in outcomes depending on prosthetic material of conduits.$^{[7]}$ The use of Dacron versus PTFE as a conduit in aortoiliac position is based on the preference of the surgeon. The main important criterions of conduit quality are inertness, histocompatibility, resistance to infection and favorable biomechanical properties (elasticity, extensibility, flexibility and durability).

According to the Trans Atlantic Inter-Society Consensus II (TASC - II), the "gold standard" of primary patency rates at 5 years and at 10 years is from $87 \%$ to $91 \%$ and from $81 \%$ to $86 \%$, respectively, in $\mathrm{C}$ type and D type of lesions. Primary patency rate is decreased in average by $10 \%$ in the patients with critical limb ischemia and/or the presence of femoropopliteal artery occlusion. ${ }^{[8,9]}$ Despite the mortality rate following aorto-bifemoral bypass procedures decreased during the last decades, the patency rate did not change. ${ }^{[10]}$ Furthermore, graft infection (mortality rate varies from $25 \%$ to $88 \%)^{[11]}$, false aneurysms ${ }^{[2]}$ and neointimal hyperplasia $^{[13]}$ did not diminish during last decades.

\section{Material and Method}

197 executive patients with aortoiliac lesions have been consecutively treated using linear or bifurcated
PTFE "Ecoflon" vascular grafts at the vascular surgery department of I.I. Mechnikov Academy in the period between 2002 and 2010. The age of the treated subjects varied from 40 to 81 years, the age median was $60.5 \pm 20.5$ years. Bilateral iliofemoral lesions were present in 121 patients $(61.4 \%)$, unilateral iliofemoral lesions in 72 subjects $(36.6 \%)$ and 4 patients had abdominal aortic aneurysm (AAA) without clinical signs of peripheral arterial disease (PAD). Males predominated in the study population (92.1\%).

Indications for surgical intervention included aortoiliac occlusive disease with grade II (34.2\%), III $(51.3 \%)$ and IV (14.5\%) chronic limb ischemia according to R. Leriche - R. Fontaine. Duration of disease varied from 6 months to 8 years. Ischemia worsened slower in the patients with II grade than in the patients with III or IV grade. Decompensation of low limb peripheral circulation during 1 year was found in more than $85 \%$ patients. Coexisting diseases were revealed in $181(91.9 \%)$ patients. The leading of them were pathology of the cardiovascular system (170 patients) such as heart failure, ischaemic heart disease, previous stroke or TIA and hypertension. More than $3 / 4$ patients were current smokers and hyperhomocysteinemia (Hcy) was diagnosed in $1 / 4$ patients.

Aortoiliac lesions were treated primarily by one of the following techniques: aorto-bifemoral bypass (113), aorto-unifemoral or iliofemoral bypass (72) and AAA repair by linear vascular graft(4). One-third of operated subjects underwent profundaplasty in order to improve distal run-off.

In-hospital (30-days) mortality, amputation rate, patency rate and complication rate were analysed in the early postoperative period. The objective (treadmill exercise and $\mathrm{ABI}$ ) and subjective (health questionnaires like Short Form 36 Health Survey (SF-36), Vascular Quality of Life Questionnaire, VascuQol) signs were assessed to define the success of the following vascular reconstruction in the early postoperative period. ${ }^{[14,15]}$

The special emphasis was placed to the complications that might be connected with the vascular conduit quality such as incidence of early graft occlusion, severe intraoperative and secondary early haemorrhage, graft infection. Primary patency, secondary patency, 
limb salvage, survival rates, infection complications and false aneurisms were assessed for evaluation of long-term results.

As factors negatively affecting the long-term results of such intervention we assessed the following: clinical stage of disease (intermittent claudication versus critical limb ischemia), quality of run off vessels, co-existing diseases, cardiovascular risk factors (smoking, dyslipidemia, chronic renal insufficiency, diabetes mellitus and others) and technical failures (uncommon sutures, widespread endarterectomy and others).

The telephone questioning, analysis of medical history, laboratory examination and imaging techniques were used in order to study the catamnesis. Additionally, ankle-brachial index (ABI) and toe systolic pressure (in patients with diabetes mellitus) were measured for evaluation of successful revascularization. Patency was assessed as per the guidelines by R.B. Rutherford et al. ${ }^{[16]}$ Patency was determined by duplex ultrasound imaging and presence of shunt pulsation.

Material for histological examination was fixed for 24 hours in $10 \%$ formaldehyde solution. A standard protocol of tissues compression and dehydration in isopropyl alcohol was used for preparing microscopic slides. These samples were then embedded in paraffin. Hematoxylin-eosin was used for those sections to be investigated by light microscopy. The light microscopy was performed with original magnification of X100, $\mathrm{X} 400$. The invasion of connective tissue, grade of arterial wall sclerosis, degree and particular kind of chronic inflammation were assessed.

Patency rates were calculated using Kaplan-Meier life-table estimates. A long-rank test, Student's t-test and $\chi^{2}$ test were used to compare the obtained results. A value of $p<0.050$ was considered as statistically significant. Statistical analysis was performed using SPSS 15.0 software (SPSS, Inc., Chicago, IL, USA).

\section{Results}

Complications in the intraoperative and early postoperative periods were observed in 15 patients $(8.8 \%)$. The majority of them was represented by graft thrombosis -9 patients $(4.6 \%)$. The leading reasons for graft thrombosis were poor runoff and technical failures dur- ing the procedures. In six of them additional reconstruction of runoff vessels was carried out for revascularization. The early secondary haemorrhages were observed in $3(1.5 \%)$ patients. The causes of them were technical failures. It is significant that haemorrhages from needle stitches observed in previous generations of conduits are not present in modern modifications. Three patients with trophic disorders developed deep wound infection involving the bypass. That required the removal of the infected bypass part. One patient was successfully treated by means extraanatomical shunting, and above-knee amputation was necessary in 2 patients. Six patients died at the hospital or within 30 days after operation. In-hospital (30-days) mortality was $2.9 \%$. The causes of death were coronary (myocardial infarction - 3) and cerebral events (stroke -1) and specific complications. ${ }^{(2)}$

The long-term outcomes were evaluated in 136 patients. Mean follow-up was $84.5 \pm 23.5$ months. Primary patency rates at 1, 5 and 9-years of follow-up were $96.9 \pm 0.36 \%, 86.5 \pm 2 \%$ and $82.2 \pm 0.8 \%$, respectively. Secondary patency rates at 1, 5 and 9-years of followup were $98.2 \pm 0.3 \%, 91.4 \pm 1.7 \%$ and $88.5 \pm 0.3 \%$, respectively. (Fig.1) Multiple lesions of infrainguinal arteries $(\mathrm{p}<0.01)$, presence of critical ischemia $(\mathrm{p}<0.05)$ and young age of the patients $(\mathrm{p}<0.05)$ reduced the patency rate. Graft thrombosis was observed in 8 patients within a period of $15-18$ months (4.1\%) after surgery and in 8

Fig-1. Kaplan-Meier survival estimate primary and secondary patency rates of PTFE "Ecoflon" vascular grafts for aortoiliac lesions.

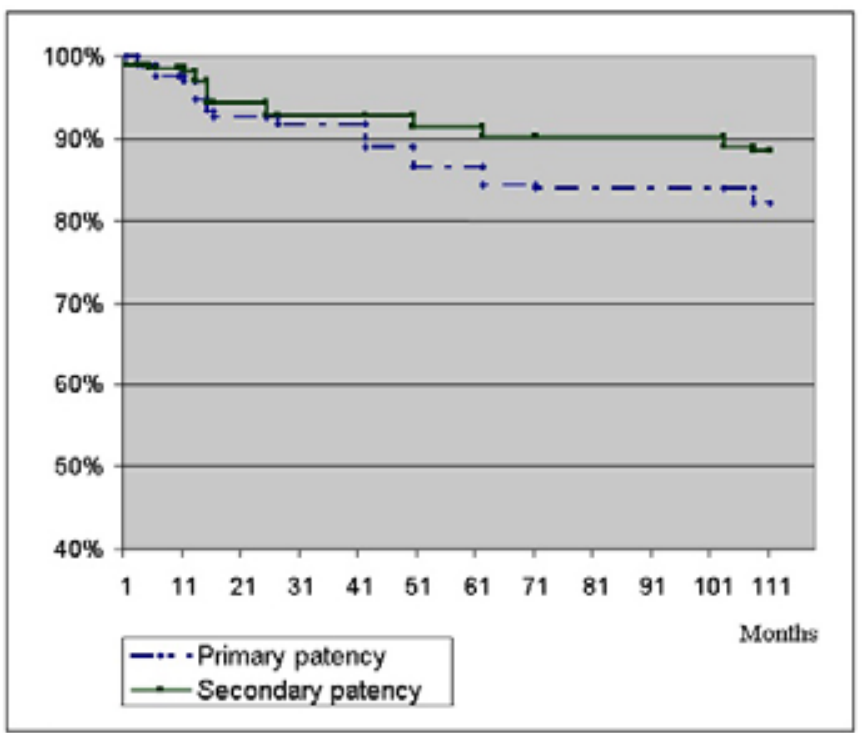




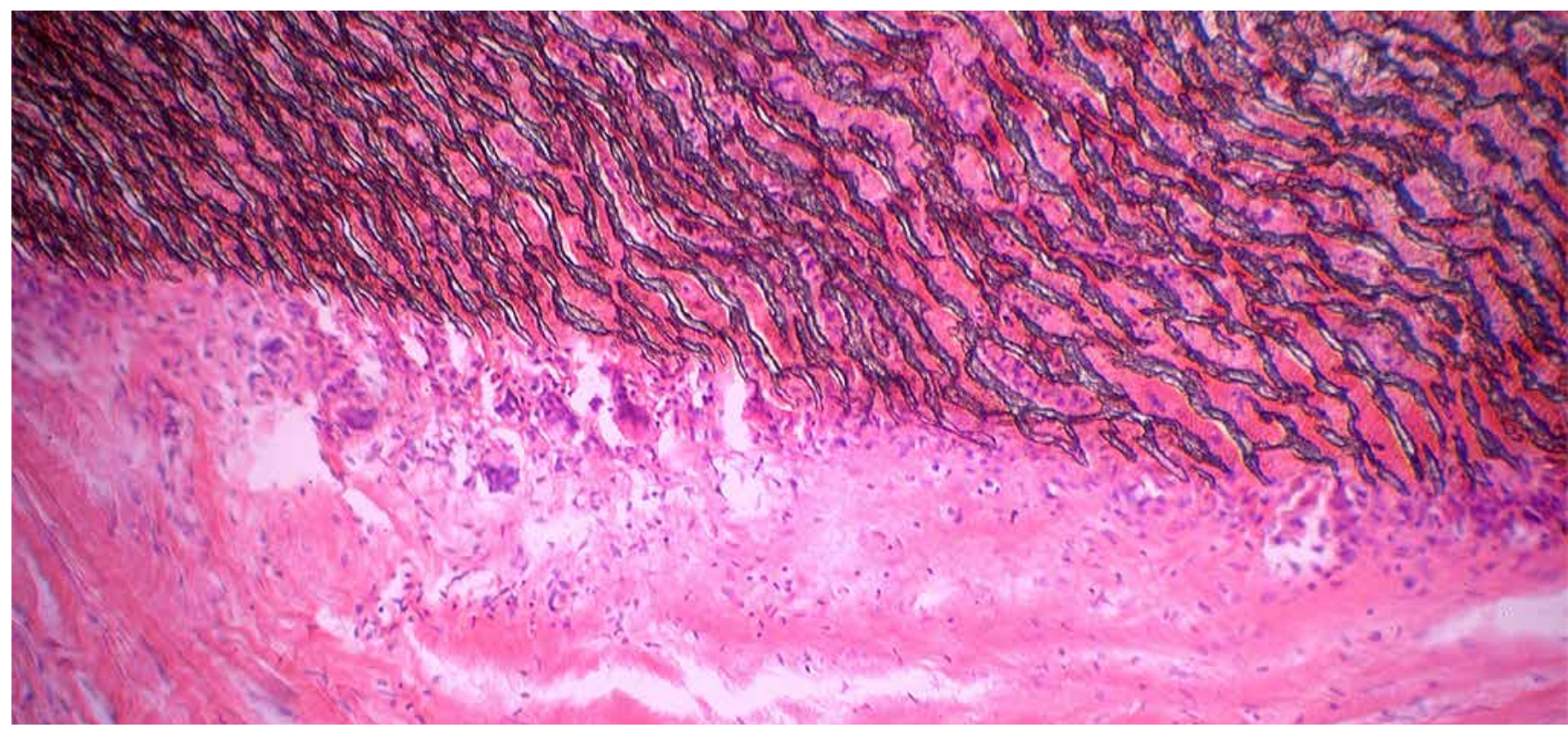

Fig-2. Light microscopy: PTFE "Ecoflon" graft 12 months after implantation in aortofemoral position. Complete coverage of outer surface of the graft with a layer of well-marked connective neoadventitial tissue without marked macrophage and neutrophil infiltration (Hematoxylin-eosin stain., original magnification $x$ 400.)

patients in later terms.

The leading reasons for graft thrombosis in the persons aged 50 years and above were neointimal hyperplasia, elevated von Willebrand factor level $(186.1 \pm 48.2 \%$ vs $144.1 \pm 37 \%$ in elderly subjects $(\mathrm{p}<0.05))$ and C-reactive protein level $(7.2 \pm 1.0 \mathrm{mg} / 1 \mathrm{vs} .5 .0 \pm 2.0 \mathrm{mg} / 1 \mathrm{in}$ elderly subjects $(\mathrm{p}<0.05))$, as well as hyperhomocysteinemia (homocysteine levels $=17.6 \pm 4.2 \mathrm{nmol} / 1$ versus $10.7 \pm 3.2 \mathrm{nmol} / 1$ in elderly patients, respectively

Fig-3. Kaplan-Meier survival estimate limb salvage rate after aortofemoral reconstruction with PTFE "Ecoflon" vascular grafts.

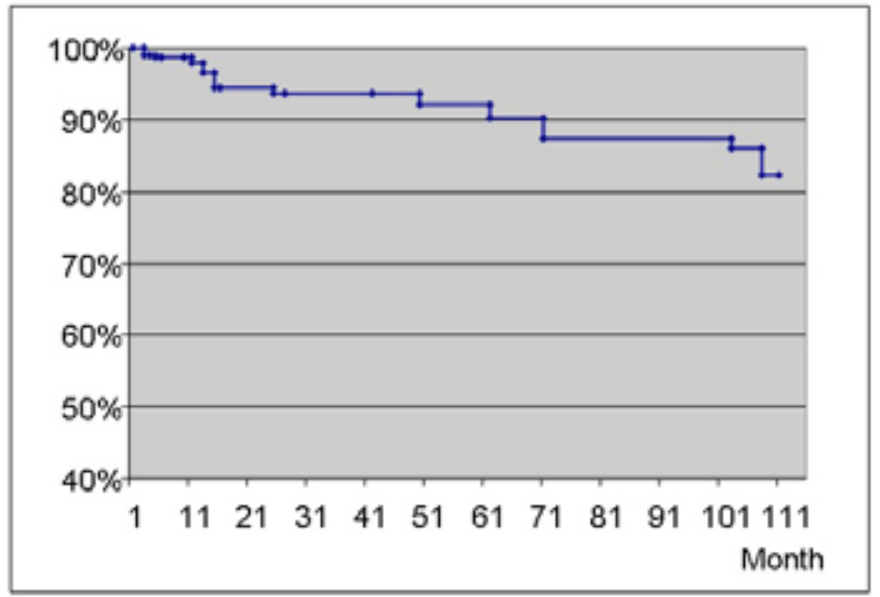

$(p<0.05)$. The dominant reasons for graft thrombosis in elderly patients (persons aged above 50 years) were progression of atherosclerotic lesions in run-off vessels, elevated activated platelets count $(28.5 \pm 4.5 \%$ vs $18.4 \pm 5.3 \%$ in young subjects $(\mathrm{p}<0.05)$ and aggregated platelets count $(8.7 \pm 2.1 \%$ vs. $5.7 \pm 1.6 \%$ in young subjects $(\mathrm{p}<0.05)$.

False aneurysms of anastomotic site occurring due to low shear friction forces in points of turbulence, stagnation and "alienation" of stream, were successfully eliminated at three patients. Histological examination of graft walls obtained during repeated interventions (later than 1 year after primary surgery) demonstrated complete covering of the graft surface by a layer of well-marked connective neoadventitial tissue without neutrophil infiltration. Minimal or moderate cellular infiltrations were found in artery walls.

These cellular infiltrations were represented by lymphocytes and plasmocytes. Furthermore, the highest possible accumulation of inflammatory cells was revealed in areas adjacent to the implant surface. Sometimes, single macrophages and gigantic cells were found. The detailed studies at our laboratory clearly demonstrated that the implant surface of each polyester fiber was surrounded by collagen fibers. 
We also observed the invasion of fibroblasts and fibrocytes to the implant surface. (Fig.2) Limb salvage rates at 1, 5 and 9-years of follow-up were $97.9 \pm 0.4 \%$, $92.1 \pm 1.24 \%$ and $82.4 \pm 3.2 \%$, respectively. (Fig.3)

Survival rates at 1, 5 and 9-years of follow-up were $95.4 \pm 0.4 \%, 84.6 \pm 1.6 \%$ and $49.2 \pm 0.8 \%$. (Fig.4) The leading reasons of death were coronary and cerebral catastrophes (68.2\%) and oncology (12.2\%).

\section{Discussion}

The PTFE "Ecoflon" vascular grafts may be used for bypass or prosthetics of any anatomical regions (except for coronaries and carotid arteries). Despite their high porosity, the "Ecoflon" vascular grafts due to optimal microporosity are not permeable even in arterial hypertension. Also, the high porosity provides for connective tissue invasion that led to formation of

Fig-4. Kaplan-Meier survival estimate surveillance rate after aortofemoral reconstruction with PTFE "Ecoflon" vascular grafts.

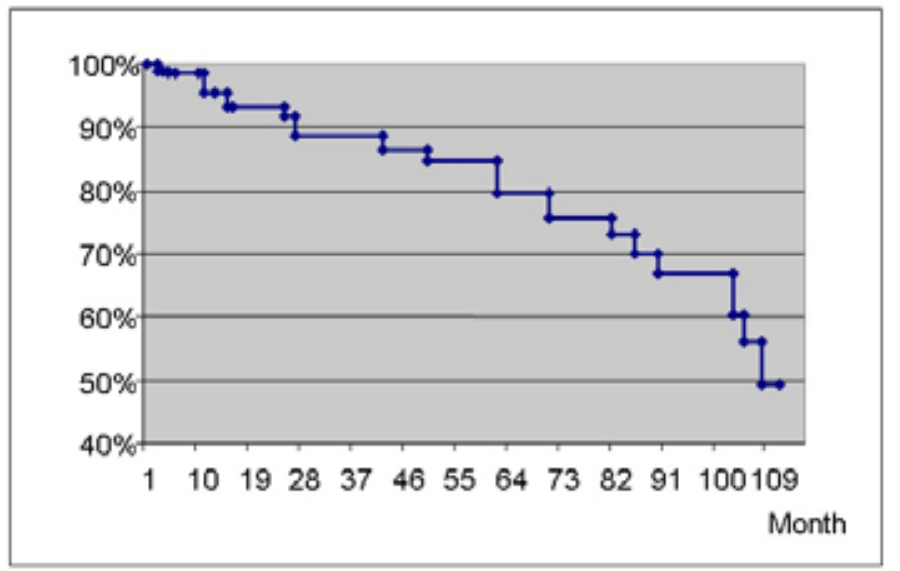

pseudointima connected with the body tissue. These vascular grafts do not require treatment with blood. These prostheses are softer and more similar to blood vessel than texture prostheses.

Also, mechanical and physical characteristics play an important role in the quality of PTFE vascular grafts. ${ }^{[22,23]}$ Our findings suggested that mechanical and physical properties of "Ecoflon" vascular grafts were comparable with vascular grafts produced by foreign companies. According to most researches, the adequate flexibility is one of the necessary criteria for artificial prosthesis. V.I. Koshev and co-workers (2007) studied a hydrodynamic flutter and antiflutter stabilization in the cardiovascular system. If the prosthesis does not support a pulse wave velocity the blood flow velocity is decreased. They documented that it could be a reason of acute occlusion. ${ }^{[24]}$ Previous studies demonstrated that the pulse wave pressure transduction in "Ecoflon" vascular graft was comparable with human femoral artery.

\section{Conclusion}

Progress in vascular surgery is closely related to research in the field of synthetic vascular grafts. From these researches, a so-called ideal vascular conduit has to meet some requirements. "Ecoflon" PTFE vascular grafts are biologically inert prostheses with the original arrangement of fibrils and structural and no surgical porosity. Grafts may be sterilized by modern sterilization methods. In addition to mentioned characteristics, favorable biomechanical properties (elasticity, extensibility, flexibility and durability) of "Ecoflon" vascular grafts provide long-term maintenance of adequate blood flow through bypass graft. 


\section{References}

1. Voorhees A.B., Jareizki A., Blakemore A.H. The use of tubes constructed from Vinion "N" cloth in bridging arterial defects // Ann. Sur. 1952. - V. 135. No. 3. - p. 332-336.

2. Dudanov I.P., Karpov A.V., Kaputin M.U. et al. Complex management of atherosclerotic lesions in the terminal part of the aorta and peripheral arteries in elderly patients. // Med. Acd. J. - 2007. - No. 1. - p. 166-172.

3. Evdokimov A.G., Rychlov I.O., Turgiev B.G. et al. Long-term results following aortofemoral reconstructions. // Angiol. and Vasc. Surg. 2001. - No. 3 (Supplement). - p. 57-58

4. Kasanchyan P.O., Popov V.A., Debeliy U.V. Long-term outcomes of aortofemoral and iliofemoral reconstruction. // Angiol. and Vasc. Surg. 2001. - No. 3 (Supplement). - p. 74-76

5. Maximov A.V., Mamaev V.E., Khalilov I.G. et al. A short incision for iliofemoral reconstruction. // Angiol. and Vasc. Surg. - 2006. - No. 2 (Supplement). - p. 106-114.

6. Melnikov M.V., Andreev V.V., Khardikov I.E. et al. Domestic PTFE vascular grafts in surgery of aortoiliac occlusions. // Angiol. and Vasc. Surg. -2008. - No. 3 (Supplement). - p. 25-26.

7. Lam M.E., Landry G., Edwards J. et al. Risk factors for autogenous infrainguinal bypass occlusion in patients with prosthetic inflow grafts // J. Vasc. Surg. -2004 . - No. 39. - p. $336-342$.

8. Norgren L., Hiatt W.R., Dormandy J.A. et al. Fowkes F.G.R. and on behalf of the TASC II Working Group Inter-Society Consensus for the Management of Peripheral Arterial Disease (TASC II) // Eur. J. Vasc. Endovasc. Surg. - 2007. - No. 33: Suppl. - p. S1-S75.

9. Diagnosis and Management of Patients with Peripheral Arterial Disease // Consensus of Russian Society Of Angiology and Vascular Surgery. M. - 2007. - p. 2003.

10. De Vries S.O., Hunink M.G. Results of aortic bifurcation graft for aor- toiliac occlusive disease: a meta-analysis // J. Vasc. Surg. - 1997. - No 26:4. - p. 58-69.

11. Balas P. An Overview of Aortofemorol Graft Infection // Eur. J. Vasc. Endovasc. Surg. - 1997. - Vol. 14. - p. 3-5.

12. Markovic D.M., Davidovic L.B., Kostic D.M. et al. False anastomotic aneurysms // Vascular. - 2007. - 15 (3): 141-8.

13. Sarkar S., Salacinski H.J., Hamilton G., Seifalian A.M. The mechanical properties of infrainguinal vascular bypass grafts: their role in influencing patency // Eur. J. Vasc. Endovasc. Surg. - 2006 Jun; 31(6): 627-36.

14. Klevsgard R., Hallberg I.R., Risberg B., Thomsen M.B. The Effects of Successful Intervention on Quality of Life in Patients with Varying Degrees of Low Limb Ischamia // Europ. J. Vasc. Endovasc. Surg. - 2000 - Vol. 19, N 3. - p. 238-245.

15. Ware J.E. Jr., Sherbourne C.D. The MOS 36-item short-form health survey (SF-36). I. Conceptual framework and item selection // Med. Care. - 1992, Jun. - Vol. 30, N 6. - p. 473 - 483.

16. Rutherford R.B., Baker J.D., Ernst C., Johnston K.W., Porter J.M., Ahn S. et al. Recommended standards for reports dealing with lower extremity ischemia: revised version. J. Vasc. Surg. - 1997 Sep; 26(3): 517-38.

17. Lebedev K.V., Plotkin L.L., Smirnov A.D. Vascular grafts. Publ. by "Medecine". Saint-Petersburg. 2001.

18. Sarkar S., Salacinski H.J., Hamilton G., Seifalian A.M. The mechanical properties of infrainguinal vascular bypass grafts: their role in influencing patency // Eur. J. Vasc. Endovasc. Surg. - 2006 Jun; 31(6): 627-36.

19. Koshev V.I., Petrov E.S., Volobuev A.P. A hydrodynamic flutter and antiflutter stabilization in the cardiovascular system. A hydrodynamic pattern and general theory of circulation. // Miocardia. - Samara: LLC "Ofort".- 2007. - p. 408.

Received: 24/07/2012

Accepted: $11 / 10 / 2012$

Published: 23/02/2013

Disclosure and conflicts of interest:

Conflicts of interest were not reported.

\section{Corresponding author:}

Dr. Vladimir Alexandrovich Zelinskiy

Mail: zelinsky2@rambler.ru 